\title{
Educação e justiça social à luz da teoria crítica da sociedade
}

\author{
Education and social justice in the perspective of the critical theory of society
}

\author{
Educación y justicia social en la perspectiva de la teoría crítica de la sociedade
}

\author{
Geraldo Balduino Horn* \\ Luciana Vieira de Lima*
}

\section{Resumo}

O presente artigo problematiza e analisa, a partir da perspectiva da teoria crítica da sociedade, a relação entre educação e justiça social na sociedade hodierna. Parte-se da hipótese de que a justiça social só existe com a eliminação das desigualdades econômicas, sociais e culturais entre os indivíduos. Nesse caso, justiça social e capitalismo são, por natureza, incompatíveis. Justiça social tornou-se mera abstração, discurso político-jurídico-ideológico das classes mais abastadas. A norma-padrão jurídica, os rituais escolares e religiosos justificam-se e operam a partir da moralidade judaico-cristã burguesa: "todos" têm direitos iguais. "Todos" os incluídos, convertidos, escolhidos ou eleitos, seja pela manifestação divina, seja pelo poder material ou político. A impossibilidade da existência de justiça social na sociedade moderna e contemporânea tem a ver com o problema da padronização e da racionalização exacerbada do processo da produção industrial e da reprodução social; com as carências e as implicações que esse modelo social provoca na vida dos indivíduos, principalmente em relação ao empobrecimento da formação cultural. Justiça social transcende o direito e a ideia de liberdade burguesa e é diametralmente proporcional à conquista de direitos sociais básicos (educação, saúde, segurança, lazer e trabalho), necessários para o bem viver. A realização plena da justiça social depende pari passu da destruição do modelo social capitalista vigente na atualidade. Nesse contexto, a educação escolar, como prática social, pode contribuir para resgatar e disseminar princípios e valores voltados à realização da justiça social.

Palavras-chave: Educação escolar. Justiça social. Teoria crítica.

Recebido em 05/02/2019 - Aprovado em 28/06/2019

http://dx.doi.org/10.5335/rep.v26i3.9321

Doutor em Educação pela Universidade de São Paulo. Pós-doutoramento em Educação, com ênfase em Educação Filosófica, na Universidade Federal de Santa Maria. Professor da linha de pesquisa Cultura, Escola e Ensino, do curso de Pós-Graduação em Educação, mestrado e doutorado, da Universidade Federal do Paraná. Brasil. ORCID: 00000003-1056-4822. E-mail: gbalduino.ufpr@gmail.com

** Possui graduação em Filosofia pela Universidade Federal do Paraná. É especialista em Filosofia e Literatura pela Pontifícia Universidade do Paraná e mestre em Filosofia pela mesma instituição. Possui doutorado em Educação, com ênfase em Educação Filosófica, pela Universidade Federal do Paraná. Brasil. ORCID: 0000-0002-8122-8503. E-mail: luna-lima@hotmail.com 


\section{Abstract}

This article discusses and analyzes, from the perspective of the critical theory of society, the relationship between education and social justice in today's society. It is hypothesized that social justice only exists with the elimination of economic, social and cultural inequalities between individuals. In this case, social justice and capitalism are by nature incompatible. Social justice has become mere abstraction, political-juridical-ideological discourse of the more affluent classes. The standard rule legal, school and religious rituals are justified and operate from bourgeois Judeo-Christian morality: "Everybody" have equal rights. "Everybody" those included, converted, chosen, or elected either by divine manifestation, by economic power or political. The impossibility of the existence of social justice in modern and contemporary society is related to the problem of standardization and rationalization exacerbated by the process of industrial production and social reproduction; with the deficiencies and implications that this social model causes in the life of individuals, especially in relation to the pauperization of cultural formation. Social justice transcends the law and the idea of bourgeois freedom and is diametrically proportional to the achievement of basic social rights (education, health, safety, leisure and work) necessary for the well-being. The full realization of social justice depends on the destruction of the current capitalist social model. In this context, school education, as a social practice, can contribute to the rescue and dissemination of principles and values aimed at achieving social justice.

Keywords: Schooling. Social justice. Critical theory.

\section{Resumen}

Desde la perspectiva de la teoría crítica de la sociedad, el artículo discute y analiza la actual relación entre educación y justicia social. Se plantea la hipótesis de que la justicia social solo puede existir con la eliminación de las desigualdades económicas, sociales y culturales entre los individuos. En ese contexto teórico, se afirma que la imposibilidad de existencia de la justicia social en la sociedad moderna y contemporánea estaría relacionada con el problema de la estandarización y de la racionalización exacerbadas por el proceso de producción industrial y reproducción social. Eses procesos contendrían las deficiencias e implicaciones que ese modelo social causa en la vida de los individuos, esencialmente en relación con el empobrecimiento de la formación cultural. Así, la justicia social y el capitalismo serian por naturaliza incompatibles. Por lo tanto, la justicia social sería una mera abstracción, un discurso político-jurídico-ideológico de las clases más acomodadas. Al mismo tiempo, se afirma que la regulación, la escuela y los rituales religiosos se justificarían y operarían desde la moral judeocristiana burguesa en que "todos" tienen los mismos derechos. En la expresión "todos" se incluyen apenas los convertidos y los elegidos por la manifestación de divino o del poder material o político. Pero, la justicia social trascendería la ley y la idea de la libertad burguesa y sería indiscutiblemente proporcional al logro de los derechos sociales básicos, necesarios para el bienestar, cómo la educación, la salud, la seguridad, el ocio y el trabajo. Por lo tanto, la plena realización de la justicia social dependería de la superación del actual modelo social capitalista. En este contexto, la educación escolar, como práctica social, podría apoyar el rescate y la difusión de principios y valores orientados al logro de la justicia social.

Palabras clave: Educación escolar. Teoría crítica. Justicia social.

\section{Introdução}

A temática justiça ocupa um lugar de destaque na história da filosofia desde os pré-socráticos. Foi tratada como um problema ético-filosófico, mas, geralmente, a partir de uma conotação abstrata, vaga, meramente conceitual, quando não a-histórica. Fala-se muito na justiça em sentido equitativo, normativo, divino ou 
mesmo comutativo, mas não em uma acepção radicalmente social como condição necessária da vida humana. Em todos os períodos da história humana (antigo, medieval, moderno e contemporâneo), foram e ainda são constantes as injustiças e as atrocidades contra pessoas pobres, mulheres, negros, índios, isto é, pessoas excluídas de toda ordem do processo social. Vários modelos hegemônicos de sociedade reforçaram as desigualdades econômicas, sociais e culturais entre os indivíduos como forma de dominação, controle e exploração, mantendo separado, portanto, o entendimento de "justiça" de sua dimensão "social”. É na contemporaneidade que, fundamentalmente, a discussão sobre a justiça passa a ter uma conotação ética associada às condições concretas da existência humana, da vida em sociedade.

A sociedade capitalista é, em grande medida, responsável por unir os termos "justiça" e "social". Uma adjetivação contraditoriamente necessária para justificar as promessas do ideário burguês de uma sociedade igualitária, fraterna e com direito de ir e vir. Daí as perguntas: é possível pensar em justiça social dentro de uma sociedade dividida em classes? Até que ponto é possível haver justiça social em uma sociedade que se fundamenta na desigualdade e na exploração do trabalho? É possível pensar em justiça social quando os aparatos jurídico e político obedecem a uma ordem econômica controlada por elites? A educação escolar pode se tornar uma prática social de superação voltada à realização da justiça social?

A ideia de justiça social teve, a princípio, no período que se seguiu à Crise de 1929 até a virada neoliberal da década de 1970, um forte apelo entre a classe trabalhadora. A regulação do mercado promovida pelo Estado de bem-estar social transformou as contradições entre o trabalho e o capital em um telos racional baseado no desenvolvimento econômico. Com isso, a ampliação da demanda incrementada pelo Estado na construção de grandes obras se justifica nos limites da conservação dessa própria ordem. Isso passou a ser considerado sinônimo de progresso social e, consequentemente, de justiça social, por meio da manutenção de índices de emprego compatíveis com a necessidade do capital. Nesse sentido, é preciso compreender os efeitos concretos e ideológicos desse modelo de Estado social, no quadro histórico da construção de valores, e das normas de legitimação da exploração, pelo viés da ideologia da justiça social e de seu alcance por meio da educação. Afirmou-se que a justiça social caracteriza-se como uma ideologia, pois os investimentos do Estado de bem-estar social não se realizaram em proveito da classe trabalhadora, mas, somente, como uma forma de gerar a demanda necessária para a manutenção do capital.

Nesse sentido, a justiça social é uma compensação, uma estabilização dos conflitos sociais. Essa estabilização, ou seja, a naturalização da exploração capitalista 
e do trabalho alienante, exige da educação um servilismo demagógico voltado à construção do pseudoesclarecimento e da qualificação para o trabalho. Por isso, o desenvolvimento econômico, como condição necessária à justiça social, torna-se limitante da construção de uma sociedade realmente livre e emancipada das formas de trabalho alienantes e reificadas. A justiça social é uma condição necessária, mas não suficiente, à plena realização da liberdade. Disso decorre a seguinte afirmação: a justiça social só se objetivará no plano social com a eliminação real das desigualdades econômicas, sociais e culturais entre os indivíduos e, portanto, com a eliminação do trabalho em sua expressão alienada.

Para efeitos de exposição, este artigo foi dividido em dois momentos. $\mathrm{O}$ primeiro mostra, principalmente a partir da leitura de autores como Laval (2004), Mészáros (2008, 2011), Streeck (2013) e Luxemburgo (2011), que justiça social e capitalismo são, por natureza, incompatíveis. Justiça social tornou-se mera abstração, discurso político-jurídico-ideológico das classes mais abastadas. A impossibilidade da existência de justiça social na sociedade moderna e contemporânea, por um lado, tem a ver com o problema da padronização e da racionalização exacerbadas do processo da produção industrial e da reprodução social, por outro, transcende o direito e a liberdade individuais e é diametralmente proporcional à conquista de direitos sociais básicos (educação, saúde, segurança, lazer e trabalho), necessários para o bem viver. O segundo tópico apresenta, a partir de Adorno e Horkheimer, a tensão entre educação escolar na atualidade e justiça social.

\section{A justiça social no capitalismo: antinomias}

No período compreendido entre a grande depressão de 1929 e a ascensão do credo neoliberal dos anos 1970, viu-se uma guinada da falência do princípio do Laissez-faire à doutrina econômica keynesiana. Conforme Shermann e Hunt (2010), quando Keynes publicou, em 1936, a sua obra Teoria geral do emprego do juro e do dinheiro, o sistema econômico ainda não havia se recuperado da bancarrota de 1929. Keynes intentava compreender o papel dos fluxos de renda na forma de salários, remunerações, rendas, juros e lucros no equilíbrio do mercado. Ele constatou que os "vazamentos" nos fluxos de renda (impostos, poupança e a aquisição de bens no mercado externo) são responsáveis pelas crises capitalistas. A solução apontada reside em utilizar o Estado para transformar "o excesso de poupança" e os "impostos" em "projetos sociais". Essa fórmula garante que o Estado não interfira diretamente nos investimentos privados, assim o processo de acumulação esta- 
ria assegurado. O Estado garantiria, por meio de grandes obras públicas em saúde, infraestrutura e educação, o pleno emprego e a renda necessária para a realização da mais-valia contida nas mercadorias. A expansão da produção capitalista, ou seja, a acumulação constante do capital, encontra-se, no modelo keynesiano, ligada à expansão constante da demanda social por meio do pleno emprego.

As práticas adotadas nesse período, em termos de justiça social, apresentaram-se, muitas vezes, ideologicamente sob a intervenção do Estado na eliminação das desigualdades sociais. Para Singer (1987, p. 52), Keynes ignorou, deliberadamente, a alternativa da "distribuição de renda [sic] como meio de elevar a demanda efetiva", pois, para o capitalista, a ideia de distribuir a parcela do capital acumulada na forma de mais-valia é contrária à necessidade constante de acumulação. Ao capitalista importa o consumo como realização da mais-valia e da reprodução da mão de obra. Se a preocupação da ortodoxia keynesiasa não é a distribuição de renda, percebe-se que o dispêndio do Estado em educação se justifica apenas para ampliar a demanda agregada (consumo), de acordo com as necessidades da economia. Ainda que o crescimento do sistema educacional pareça um esforço constante do Estado para ampliar o nível educacional para um número cada vez maior da população, esse gasto justifica-se apenas na lógica de ampliação do capital, e não na distribuição das condições para os plenos desenvolvimentos intelectual, cultural, científico, etc.

De forma análoga às críticas de Singer, outro autor demonstra os limites da justiça social dentro da perspectiva do Estado de bem-estar social keynesiano. Para Marsden (1974, p. 114), "a justiça social não pode ser promovida apenas por atividades residuais, por programas especiais de criação de empregos fora das prioridades básicas do planejamento econômico, ou por transferências dos ricos para os pobres através de subsídios ou doações”.

A ampliação da produtividade, entretanto, permitiu estabelecer um consenso entre forças antagônicas. Os gastos do Estado se converteriam em salário maiores, que implicariam o acesso à educação formal, esta garantidora, por sua vez, de empregos com melhores salários. A justiça social como resultado da sucessão, geralmente ininterrupta e infinita, de empego, renda e consumo transformou a "luta de classes" em uma luta solidária entre o capital e o trabalho. Curiosamente, os "avalistas" dessa luta solidária foram os "barões dos sindicatos nacionais", recompensados com o "fortalecimento da democracia e da justiça social, sem negar o capitalismo como fonte da prosperidade futura. Os interesses do capital estariam garantidos graças à gestão econômica da nação, à paz social e à produtividade crescente" (ELEY, 2005, p. 367). 
Essa luta solidária proporcionou oportunidades de renda e de consumo a que muitos trabalhadores jamais tinham tido acesso. Aqueles que conseguiram um emprego ajustaram-se ao aparato e logo trataram de utilizar as economias em forma de poupança para ampliar a renda por meio da educação. Os velhos ideais de emancipação foram reinterpretados pela abertura, mesmo limitada, ao reino do capital. Deixando de lado os horrores de um passado recente, a defesa de posições conciliatórias afundou, gradativamente, a proposta radical de uma nova sociedade. A sociedade civil-burguesa permanece no horizonte, e as relações econômicas ficam protegidas no interior dessa sociedade pelo uso aparente da democracia.

O abandono da teoria crítica marxista desse período reduziu o capitalismo a um modo de produção capaz de distribuir igualmente a renda, bastando, para isso, o desenvolvimento de estratégias de legitimação no interior do Estado. Esse "reformismo" conduziu a uma falsa interpretação do funcionamento do capitalismo e, consequentemente, a uma interpretação também superficial da justiça social e da educação. Para Streeck (2013, p. 7), ao substituir a "teoria econômica pela teoria do Estado e da democracia", a teoria crítica abandona, em seu prejuízo, "uma peça nuclear da herança da economia política marxista".

Deve-se admitir que o entusiasmo libertador do mercado, ao estabelecer ideias abstratas de justiça social, produziu os mais brilhantes adversários da própria liberdade, pois formalizou um tipo de teoria e de prática de adaptação da economia capitalista, promovendo um amálgama entre o proletariado e a burguesia - uma concepção distante da visão dialética e revolucionária marxista.

Nesse ponto, pode-se, por exemplo, observar a relevância das teses de Rosa Luxemburgo sobre as limitações objetivas do reformismo. Para Luxemburgo (2011), a ideia de um capitalismo controlado, visando a criar artificialmente uma sociedade livre das desigualdades pela "eliminação dos abusos, e não do capitalismo", apresenta-se como uma construção ingênua e ilusória diante da tarefa histórica do proletariado. Ingênua, pois, ao abandonar os "objetivos finais" pelo "interesse imediato", a justiça torna-se um "cavalo de batalha" a serviço da industrialização patrocinada pelo Estado e financiada pelo aumento dos impostos sobre a população. Daí resulta um certo cinismo, pois as políticas públicas voltadas à justiça social, na verdade, apresentam-se como uma "transferência do consumo", das mãos da classe trabalhadora para o Estado.

À medida que o Estado de bem-estar social se estende para o fortalecimento "artificial”, o que está em jogo é a transformação da propriedade pública em propriedade estatal, por isso mesmo, uma vez que 
[...] as relações de produção da sociedade capitalista aproximam-se cada vez mais da socialista, todavia, suas relações políticas e jurídicas erigem um muro cada vez maior entre a sociedade capitalista e a socialista. Esse muro não é destruído pelo desenvolvimento de reformas sociais como a democracia, mas, pelo contrário torna-se mais forte e mais alto (LUXEMBURGO, 2011, p. 37).

A adoção do reformismo, como princípio político, econômico e social, atribui à educação, como instância de mediação, um papel exclusivamente idealista. Com isso, o desenvolvimento da consciência por meio da educação crítica, sob a estratégia de salvação keynesiana, ou mesmo sob a ideologia reformista e liberal do capitalismo, situa-se muito aquém de resultados objetivos de uma educação verdadeiramente crítica que pretenda romper com as leis do desenvolvimento capitalista.

Assim sendo, é preciso evitar uma tomada de posição relativista sobre a possibilidade de escolha entre duas alternativas aparentemente diferentes, mas limitadas à lógica do capital.

Dois princípios de distribuição concorrentes que eu gostaria de designar como justiça de mercado e justiça social. Por justiça de mercado entendo a distribuição do resultado da produção de acordo com a avaliação pelo mercado dos desempenhos individuais dos envolvidos, expressa através dos seus preços relativos. $\mathrm{O}$ critério de remuneração que corresponde à justiça de mercado é a produtividade limite, portanto o valor de mercado da última unidade de produção extraído de acordo com as condições da concorrência [...]. A justiça social, pelo contrário, rege-se por normas culturais e baseia-se no direito estatutário, não no direito contratual. Rege-se por conceções [sic] coletivas de honestidade, equidade e reciprocidade, concede direitos a um nível mínimo de vida da comunidade, à proteção do emprego, à organização sindical etc. (STREECK, 2013, p. 99, grifos do autor).

Essas duas formas de justiça, a princípio, fundamentalmente, rivais, tornam-se alternativas viáveis entre si, pois, diante da estratégia reformista, o modelo capitalista que funciona dentro de uma espécie de acordo entre os interesses objetivos e subjetivos, ou seja, entre os limites materiais e da consciência, implica a aceitação do modo de produção capitalista, por se "[...] conformar com a regra geral preestabelecida da reprodução da sociedade" (MÉSZÁROS, 2008, p. 26).

A representação idealista do papel da educação, isto é, que aposta na alternativa do desenvolvimento apenas da razão e do pensamento como via de libertação das determinações históricas e materiais, desempenha um processo bem planejado de internalização e de sustentação de uma determinada prática social, em harmonia, cada vez maior, com o status quo. Assim, o ponto de partida mais natural para a conquista da justiça social parece ser a transformação social por meio da reflexão crítica. No entanto, ao se considerar a educação, principalmente a formal, como desenvolvimento da reflexão crítica, independentemente de ação objetiva para a con- 
quista da liberdade, essa fórmula limita-se a um discurso ideológico. Nesse ponto, Marx e Engels (2003, p. 100, grifos dos autores) argumentam que "para levantar-se não basta apenas levantar-se em pensamento, deixando que sobre a cabeça real $\mathrm{e}$ sensível permaneça flutuando o jugo real e sensível, que nós não logramos fazer desaparecer por encanto através das ideias".

Sobre esse idealismo utópico, Mészáros (2008, p. 30) apresenta o exemplo de Robert Owen. Para Owen, importante socialista utópico, a educação moral dos operários poderia promover a superação do sistema capitalista. Se os "inconvertíveis" - aqueles que não conseguem pensar a realidade além dos limites do capital - tivessem acesso ao conhecimento, isso os libertaria do sistema capitalista, ou seja, a "cura" viria pela "razão" e pelo "esclarecimento".

O pensamento sem a práxis, aqui entendida como "ação e reflexão dos homens sobre o mundo para transformá-lo" (FREIRE, 2013, p. 52), com efeito, não leva à "ruptura com as ilusões confortadoras que têm como pressuposto que os modos em que nossas sociedades e seus aparatos educacionais estão atualmente organizados podem levar à justiça social" (APPLE; AU; GANDIN, 2011, p. 14). Sob o impacto do aparato educacional expresso nos indicadores de desempenho, de qualidade e de eficiência, inspirados em um padrão de racionalidade, "os valores de verdade críticos se tornam valores tecnológicos. Por exemplo, a afirmação de que todo indivíduo possui certos direitos inalienáveis é uma afirmação crítica, mas frequentemente foi interpretada em favor da eficiência e do poder" (MARCUSE, 1999, p. 85).

A teoria do capital humano é um exemplo dessa "ilusão confortadora". Essa teoria estabeleceu, em pleno auge do desenvolvimento industrial da metade do século passado, uma conexão particular, ao reunir, sob a mesma lógica, as perspectivas de justiça social e de justiça de mercado. Essa utopia econômica, derivada da educação como mobilidade social, foi, em parte, responsável pela "impotência social do pensamento crítico, facilitada pelo fato de que setores importantes da oposição foram há muito incorporados ao próprio aparato - sem perder o título de oposição" (MARCUSE, 1999, p. 85). O mesmo pensamento vale para a constatação de Laval (2004, p. 26), quando o autor demonstra "que os partidos de esquerda e os sindicatos retomaram por seu lado", nos anos 1970, esse raciocínio para a legitimidade que ele parecia trazer aos esforços do Estado em matéria de ensino público. 


\section{Justiça social na escola: limites e possibilidades}

Para pensar uma educação escolar que privilegie o humano e, em decorrência, a justiça social, é preciso insistir em uma formação emancipatória e libertadora, para que o educando consiga exercer sua cidadania; para tanto o pensamento crítico e autorreflexivo é substancial. Entretanto, é imprescindível que o(a) professor(a) tenha a consciência das contradições da realidade social na qual se encontra, bem como das reais condições de vida da população e dos limites que o sistema impõe, já que os seres humanos não são "apenas um resultado da história em sua indumentária e apresentação, em sua figura e seu modo de sentir, mas também a maneira como veem e ouvem é inseparável do processo de vida social, mas tal como este se desenvolveu através dos séculos" (HORKHEIMER, 1983, p. 125). Sendo assim, o(a) educador(a) precisa, sobretudo, discernir a respeito da sua realidade, bem como da de seus educandos, para projetar possibilidades de uma educação crítica, frente às dificuldades que a impedem, daí a imperiosidade de um pensamento autorreflexivo constante.

É preciso frisar que se vive em uma sociedade alicerçada pelo capitalismo, que traz, em seu bojo, alguns antagonismos - tais como: a dominação, a desigualdade, a massificação e a violência - e que, por sua vez, coloca algumas implicações no campo da educação escolar. Então, pode-se afirmar que a atualidade é marcada pela semiformação, elaborada e reelaborada de maneira incessante, reproduzida pela indústria cultural, que se propaga em todas as esferas da vida. Dessa forma, as instituições escolares não escapam a esta lógica, que é alicerçada pelo pragmatismo-positivista, que não propicia o desenvolvimento da autonomia, negando a própria formação.

Para Adorno (2005, p. 52), a semiformação "é o espírito conquistado pelo caráter de fetiche da mercadoria”. Assim, as pessoas modelam suas vidas a partir do princípio da equivalência, incluindo as relações sociais, que passam a ter o caráter de utilidade, alienando o espírito e a consciência, legitimando a exclusão social, já que o interesse individual coíbe o interesse coletivo no sentido social.

No que tange ao campo educacional, em seu texto Teoria da semicultura (2005), Adorno elabora uma crítica de como a formação (Bildung) transformou-se em semiformação (Halbbidung), alertando para o fato de que, por mais significativas que possam ser as reformas pedagógicas, elas não alcançam sozinhas as questões estruturais desse sistema, porque estão perpassadas por um processo social que, de maneira drástica, modifica a disseminação da cultura e das suas manifestações. 
Quando as reformas são destituídas de pensar, as contradições sociais e os seus próprios conceitos, como historicamente construídos, podem gerar consequências adversas, reforçando a ideologia vigente.

A adesão à ideologia capitalista tem concebido indivíduos frustrados, alienados, coisificados e frios. Os seres humanos se tornaram reificados, pois se transformaram em meros objetos, promovendo um enfraquecimento das relações humanas, o qual não possibilita que um ser humano considere o outro enquanto tal, mas, sim, como um simples instrumento para realização de seus interesses. Nessa conjuntura, parece que alguns conceitos, como pensamento crítico, autonomia, liberdade, justiça social e conscientização, foram distorcidos pelo uso ideológico - a partir da fundamentação e da normatização de cunho burguês, que têm, como pano de fundo, uma herança iluminista de que todos os indivíduos possuem os mesmos direitos e, logo, são iguais -, pois, mesmo que se tenha direitos assegurados em forma de lei, não significa que, na vida cotidiana, esses direitos sejam efetivados de fato. Isto leva à reflexão de uma incapacidade de se apreender o passado e compreender a historicidade em que se assenta o presente. Entretanto, para compreender a vida imediata, é preciso "investigar sua configuração alienada" (ADORNO, 1992, p. 7), compreendendo-a como a dificuldade de conceber que tanto a educação quanto a cultura são elementos sociais historicamente forjados.

Desse modo, faz-se necessário recuperar a célebre afirmação adorniana de que a "exigência que Auschwitz não se repita é a primeira de todas para a educação" (ADORNO, 2003, p. 119). Para Bauman (1998, p. 12), este é um fato que precisa ser tomado como desesperador, porque o

[...] holocausto nasceu e foi executado na nossa sociedade moderna e racional, em nosso alto estágio de civilização e no auge do desenvolvimento cultural humano, e por essa razão é um problema dessa sociedade, dessa civilização e cultura. A autocura da memória histórica que se processa na consciência da sociedade moderna é por isso mais que uma indiferença ofensiva às vítimas do genocídio. É também um sinal de perigosa cegueira, potencialmente suicida.

Auschwitz deve ser compreendido não como um problema alemão isolado, mas tomado como uma questão inerente à humanidade. As atrocidades e toda a indiferença que ali ocorreu servem de alerta, para que a consciência histórica não se atrofie. O que a história tem asseverado é o fato de que as diversas formas de violência e de perseguições se voltam, sobremaneira, para aqueles que são mais fracos socialmente; dessa forma, tal repetição pode ocorrer, novamente, em nome de qualquer ideia, contra qualquer grupo (ADORNO, 2003). 
A educação no contexto adorniano assume um papel preponderante para aqueles que buscam uma sociedade mais crítica e justa. A sua acepção manifesta-se de maneira mais ampla, abarcando várias instâncias da cultura, como a escola e a família. A educação deve salvaguardar tanto o indivíduo quanto a civilização, isso quer dizer que o seu papel é preservá-los ao máximo, não sendo apenas um mero adaptar-se no âmbito social ou, somente, desenvolver no indivíduo suas potencialidades para se inserir no mercado. Nesse sentido, a educação escolar que almeja transpor o status quo precisa assumir um caráter de formação (Bildung) que exprime autonomia e emancipação. Portanto, "a única concretização efetiva da emancipação consiste em que aquelas poucas pessoas interessadas nesta direção orientem toda a sua energia para que a educação seja uma educação para a contradição e para a resistência" (ADORNO, 2003, p. 183). Assim, a formação precisa considerar a configuração social e a realidade atual em que ela se dá.

A educação escolar precisa atentar-se, sobremaneira, à indiferença, à frieza e ao ódio, pois,

[...] se as pessoas não fossem profundamente indiferentes em relação ao que acontece com todas as outras, executando o punhado com que mantêm vínculos estreitos e possivelmente por intermédio de alguns interesses concretos, então Auschwitz não teria sido possível, as pessoas não o teriam aceito (ADORNO, 2003, p. 134).

Isso remete, diretamente, à questão da justiça social, pois, se a civilização atual tem como base a indiferença, parece que a preocupação com o outro não é um problema. Ainda a esse respeito, Forrester (1997, p. 41) sublinha que a indiferença é feroz: "Ela constitui o partido mais ativo e certamente o mais poderoso. Ela permite todas as exações, os desvios mais funestos, mais sórdidos". A indiferença e a frieza são produzidas e reproduzidas pela própria ordem social, elas a constituem. Percebe-se, então, que a indiferença se coloca como um empecilho não só para a justiça social, mas também para a própria educação escolar.

A educação que propõe a formação precisa ir contra qualquer forma de preconceito, ocasionando e promovendo relações de amizades entre os alunos, opondo-se aos processos de coletivização que trazem em seu bojo uma certa exclusão do que lhe é diferente. Destarte, é necessário compreender como a modernidade se assentou.

Adorno e Horkheimer (1985) elaboraram uma crítica contundente à modernidade, sem perderem de vista os elementos e as especificidades históricas que a sedimentam. A análise ressalta o fato de a cultura moderna privilegiar o ego - eu -, promovendo uma subjetividade exacerbada, alicerçando o "eu mesmo", enaltecendo o indivíduo e o distanciando do outro, afastando as possibilidades do reco- 
nhecimento do outro como sujeito tal qual um eu; logo, a alteridade se torna um problema.

Tal proposição é alicerçada na herança da filosofia cartesiana, que estabelece o sujeito como categoria fundamental; desse modo, a consciência é apenas de si subjetividade -, mas não do outro como igual. Tal distanciamento apresenta-se, na atualidade, como um problema ético, já que aquela se baseia em uma sociedade de indivíduos, ressaltando um egocentrismo e um individualismo; isso quer dizer que o sujeito, na sua constituição, não considera o outro como parte da sua formação, predominando uma consciência de si, sem a consciência do outro. É importante destacar que, para Horkheimer e Adorno (1973, p. 47),

A vida humana é, essencialmente e não por mera casualidade, convivência. Com esta afirmação, põe-se em dúvida o conceito do indivíduo como unidade social fundamental. Se o homem, na própria base de sua existência, é para os outros, que são seus semelhantes, e se unicamente por eles é o que é, então a sua definição última não é a de uma indivisibilidade e unicidade primárias mas, outrossim, a de uma participação e comunicação necessária com os outros. Mesmo antes de ser indivíduo o homem é um dos seus semelhantes, relaciona-se com os outros antes de se referir ao eu, é um momento das relações em que vive, antes de poder chegar, finalmente, à autodeterminação.

Percebe-se que, para ser um eu, existe a necessidade de se relacionar com os outros. Entretanto, há a ideologia de que existe uma independência entre a sociedade e o indivíduo, a qual, ao ser assegurada socialmente, atua como uma força objetiva nas determinações pessoais, levando o indivíduo a um certo isolamento, impossibilitando-o de ter a autoconsciência de ser histórico.

No entanto, ainda que a sociedade hodierna seja massificada, as pessoas que nela se encontram acreditam que estão em uma sociedade de indivíduos, que seus desejos e suas opiniões sejam, de fato, livres e autônomos, comportamento este que não aceita e não reconhece não só a individualidade, mas também a subjetividade do outro, produzindo um abismo nas suas relações. Adorno convida a pensar a alteridade em uma sociedade alicerçada no privilégio do eu. Segundo Adorno (2003, p. 143), a "própria organização do mundo em que vivemos e a ideologia dominante [...] exerce[m] uma pressão tão imensa sobre as pessoas que supera[m] toda a educação. De certo modo, emancipação significa o mesmo que conscientização, racionalidade". Isso quer dizer que, no sistema no qual se está inserido, não é possível negar o caráter de adaptação da educação escolar, já que existem determinadas necessidades sociais. Mas é preciso ir além deste estágio, incentivando o pensamento crítico, para que o educando não se aliene de si próprio, situando-se apenas no 
campo das condições objetivas sociais, é preciso orientar-se e situar-se no mundo, e não dele fazer parte de maneira amorfa.

Ante tal problemática, ficam explícitos que a educação escolar tem como tarefa trabalhar com a questão da alteridade e que, para a construção de um eu, é necessário o reconhecimento do outro, do que é diferente e, ao mesmo tempo, não o é, porque ambos estão inseridos em uma mesma realidade. É preciso opor-se a uma "tal ausência de consciência, é preciso evitar que as pessoas golpeiem para os lados sem refletir a respeito de si próprias. A educação só tem sentido unicamente como educação dirigida a uma auto-reflexão crítica" (ADORNO, 2003, p. 121). A educação escolar precisa promover o exercício reflexivo nos seus educandos, para que eles se constituam como sujeitos e indivíduos de uma realidade social, para que não caiam nas armadilhas da coletividade cega ou das ideologias vigentes que não promovem as diferenças nem a autonomia.

Isto é, para que conceitos como o de justiça social não fiquem apenas no campo abstrato, ou seja, esvaziados, é indispensável conscientizar para as diferenças e para as contradições do próprio sistema, pois, somente desta maneira, é possível pretender alguma transformação social. Nesse âmbito, Adorno (2003) coloca uma questão fundamental "do para que da educação". Ele chama atenção para a necessidade e para a relevância de se debater sobre o ato de educar, isto significa que a questão não deve mais caminhar no sentido de pensar qual é o fim da educação, mas, especialmente, "para onde a educação deve conduzir". A educação precisa, também, preocupar-se com a sensibilização. Nessa perspectiva, ela deve atentar-se também com o processo, não apenas com o fim.

Diante da realidade em que se vive, as informações passaram a ter cada vez mais fluxo e rapidez, o próprio processo de conhecimento, que precisa de um determinado tempo de reflexão, parece perder espaço para a imediatez e para o fugaz. O que importa não é mais o que se sabe, mas o quanto de informações se adquiriu, e, nesse caminho, o pensamento crítico não possui espaço, não há tempo para discernimento, para se questionar o porquê de determinadas coisas ocorrerem. As pessoas tornam-se apáticas frente ao que acontece com os outros, ficando inertes, ratificando um comportamento de que as coisas sempre foram assim e de que não é possível mudá-las. $\mathrm{Na}$ atualidade, a frequente divulgação de tragédias, problemas e indiferenças sociais faz que estas padeçam de invisibilidade, pois a capacidade de desenvolvimento de empatia vai se perdendo. O frenesi de informações parece isentar o indivíduo de qualquer compromisso, reforçando a consciência coisificada. 
Neste ínterim, a semiformação firma-se como formação, e as pessoas sentem-se aptas a formular opiniões sobre qualquer assunto, sem, contudo, aprofundarem-se em nenhum deles, concebendo uma realidade totalmente abreviada, prejudicando a percepção; não compreendem que são apenas semiformadas, que seus pensamentos partem de elementos estereotipados, que servem para disseminar rótulos em relação às pessoas e às coisas, sem se preocuparem com as consequências que suas ações provocam na vida social.

A advertência de Adorno, a respeito do para que educação, parece não ter perdido sua atualidade. O filósofo nos convida a analisar o real significado da educação escolar a partir dos seus problemas atuais. Tanto os professores quanto todos aqueles que estão envolvidos com a escola necessitam de uma compreensão concreta do que se deseja com a educação, as questões basilares são: estamos educando para quê? Apenas para o mercado e para a adaptação?

Assim, os problemas cotidianos parecem estar além, mesmo quando, em documentos oficiais, aparece a asserção de que é preciso formar para a cidadania e, também, para o pensamento crítico. Isso, porque essas questões aparecem de forma abstrata, como uma espécie de ornamento na burocracia, como bem adverte Pucci (2011, p. 133, grifo do autor), que os professores, em sua maioria, acabam desenvolvendo "o conteúdo e as metodologias de sua disciplina de maneira autoritária, repassando clichês, despejando em seus formandos 'saberes' estabelecidos e muitas vezes superados [...]”.

É notório que não há um projeto educacional totalmente isento de interesses, e é neste âmbito que é preciso compreender que a educação escolar modela as consciências de seus educandos a partir de determinados interesses políticos. Assim, ela "passa ser responsável politicamente pelos resultados que se tem na articulação da vida social" (BITTAR, 2007, p. 314), pois, como uma atividade intencional, a educação escolar configura-se como um projeto cuja finalidade precisa ser pensada não apenas por instâncias políticas. Mas, sobretudo, ela deve configurar-se e ser movida a partir da realidade e da necessidade social, não sendo subserviente apenas aos interesses do capital, visto que os maiores interessados em conservar as estruturas do status quo são os mesmos que influenciam um discurso de transformação, mas que nada traz de mudança.

Percebe-se que a educação é, em si, um ato político, mas o que precisa ser valorizado é que uma sociedade que busca efetivamente uma democracia precisar insistir em uma educação para o pensar, que 
Evidentemente não a assim chamada modelagem de pessoas, porque não temos o direito de modelar pessoas a partir do seu exterior; mas também não a mera transmissão de conhecimentos, cuja característica de coisa morta já foi mais do que destacada, mas a produção de uma consciência verdadeira. Isto seria inclusive da maior importância política; sua idéia se é permitido dizer assim, é uma exigência política. Isto é: uma democracia com o dever de não apenas funcionar; mas operar conforme seu conceito, demanda pessoas emancipadas. Uma democracia efetiva só pode ser imaginada enquanto uma sociedade de quem é emancipado (ADORNO, 2003, p. 141-142, grifo do autor).

A perspectiva adorniana de educação escolar preconiza o não retorno da barbárie e de movimentos totalitários, assim, ela precisa ser capaz de preparar os educandos para a sua autonomia, a fim de que eles possam compreender e analisar o presente e perceberem que decisões na esfera individual acarretam consequências na vida social e coletiva. Desse modo, a emancipação não corresponde a um sujeito isolado, mas como parte do social; a formação deve operar como uma instância mediadora entre a cultura e o indivíduo.

Segundo o filósofo, a educação escolar precisa investir na primeira infância e, nessa etapa, iniciar um processo de desbarbarização, no âmbito social, como no fato de "desacostumar as pessoas de se darem cotoveladas. Cotoveladas constituem sem dúvida uma expressão de barbárie" (ADORNO, 2003, p. 162). Além disso, a educação escolar deve estimular menos a competição e mais a necessidade do trabalho colaborativo e em grupo. E, ainda, o sistema educacional deve contribuir, efetivamente, para que "as pessoas comecem a ser inteiramente tomadas pela aversão à violência [...]” (ADORNO, 2003, p. 165). Para se alcançar transformações com esta finalidade, é preciso trabalhar as consciências coisificadas em prol de uma formação humana.

Contudo, é importante destacar que a educação escolar precisa atentar-se à questão da socialização, porque, no sistema capitalista, ela se baseia na dominação, bem como na "forma da subordinação de todos à lei da troca, sob pena de sucumbir [...]" (ADORNO, 2008, p. 110). Nessa perspectiva, os seres humanos são reduzidos a um "conceito funcional", na "redução dos homens a agentes e portadores da troca de mercadorias se oculta a dominação dos homens pelos homens" (ADORNO, 2008, p. 109). Neste âmbito, é preciso que os/as professores/as compreendam que as práticas culturais forjam as consciências, sendo, então, necessária uma crítica permanente, que "significa propriamente o mesmo que recordação, isto é, mobilizar nos fenômenos o que fez que estes se tornaram aquilo em que se converteram, para assim apreender uma outra possibilidade de vir-a-ser e converter-se em algo outro" (ADORNO, 2008, p. 336-337). 
A educação escolar que almeja a efetivação da justiça social precisa recuperar a criticidade, para que esta não seja apenas uma abstração ou um pressuposto conceitual, possibilitando tornar conhecido aquilo que não é facilmente capturado pela percepção, como bem adverte Maar (2012, p. 19):

Ainda que seja impossível mudar o passado, pode-se mudar a relação do passado com o presente pela crítica às condições que tornaram efetiva, no passado, uma determinada possibilidade. Mas apreender essa possibilidade depende de operar com categorias sociais dotadas de uma dimensão temporal e não com conceitos nos moldes do idealismo.

Destarte, a educação escolar não pode abster-se da sua dimensão adaptativa, mas, também, não deve fazer dela o seu fim, reforçando a perpetuação da ideologia vigente, haja vista que as pessoas precisam sobreviver. Contudo, o que precisa ser trazido à baila e confrontado é o fato de o sistema educacional privilegiar apenas a lógica do mercado, o que, por sua vez, assegura a injustiça social, pois, ao se embasar nos interesses mercadológicos, favorece o discurso da meritocracia, incentivando, cada vez, mais a competição; tal postura intensifica as desigualdades, porque mascara os reais problemas sociais.

A busca por uma sociedade emancipada não é tarefa apenas da escola, mas, sem ela, não será possível sua realização. Assim, pensar em uma potencial transformação social, hodiernamente, requer articulá-la à própria educação escolar. Já no que concerne o conceito de justiça social no campo educacional, é preciso empenhar-se no trabalho de transpor o uso comum deste conceito - relacionado apenas à destruição de bens na sociedade -, sendo necessário insistir na questão da apropriação da educação e da cultura pelas pessoas mais desfavorecidas, ou seja, permitir acesso a determinados bens culturais não significa apenas usufruir deles, mas entendê-los como possibilidade de transformação.

\section{Considerações finais}

A educação crítica deve existir no desvelamento das ideias dominantes provenientes da base do sistema. Nesse sentido, deve-se reconhecer que esse exercício enfrenta formas de "Liberdade que se confunde com a manutenção do status quo. Por isso, se a conscientização põe em discussão este status quo, ameaça, então, a liberdade" (FREIRE, 2013, p. 33).

O desafio histórico, como lembra Mészáros (2011, p. 138), envolve a superação da superestrutura política e jurídica, com suas raízes no processo produtivo. $\mathrm{Na}$ mesma direção, Streeck (2013) reforça que é preciso abandonar a fórmula de paz 
social e dos ideais abstratos de justiça social contidos no crescimento. É preciso promover uma democracia sem capitalismo e uma lógica de trabalho associada ao tempo livre, à valorização de cultura de nível superior e à produção de bens que não impactem de forma destrutiva na natureza.

No esforço de buscar uma educação para a autonomia, Paulo Freire assevera que o fato "de me perceber no mundo, com o mundo e com os outros me põe numa posição em face do mundo que não é a de quem a ele se adapta, mas de quem nele se insere. É a posição de luta para não ser apenas objeto, mas sujeito da história" (FREIRE, 2018, p. 53, grifo do autor). Para que isso ocorra, o professor é preponderante, pois cabe a ele a autoavaliação crítica da sua prática educativa e a necessidade de repensá-la sempre, no esforço de transpor a educação acrítica e produtivista.

Portanto, pensar em uma educação escolar que não trate a justiça social apenas como um conceito abstrato, os que com ela estão envolvidos devem olhar para a sua realidade com seriedade e inquietação, promovendo a criticidade e buscando diminuir a distância entre racionalidade, sensibilidade e humanidade. É necessário investir na alteridade e não apenas na moralidade.

Para que uma sociedade faça valer a justiça social, precisa-se promover a formação de cidadãos efetivos. O indivíduo formado seria aquele que consegue, de maneira consciente, enxergar-se como sujeito da realidade na qual se encontra, comportando-se como interventor dela, conhecedor da sua capacidade e relevância na elaboração e na reelaboração da sociedade e da educação, promovendo uma convivência civilizada e respeitando as diversidades, consciente das desigualdades e injustiças sociais que são inerentes ao sistema capitalista.

Uma sociedade que não se articula para refletir sobre suas reais condições de educação está fadada a promover a barbárie, enquanto o que precisamos é de mais civilização.

\section{Referências}

ADORNO, T. W. Educação e emancipação. 3. ed. Tradução de W. L. Maar. Rio de Janeiro: Paz e Terra, 2003.

ADORNO, T. W. Introdução à sociologia. Tradução de W. L. Maar. São Paulo: Editora da Unesp, 2008.

ADORNO, T. W. Minima moralia: reflexões a partir da vida danificada. Tradução de L. E. Bicca. São Paulo: Ática, 1992. 
ADORNO, T. W. Teoria da semicultura. Tradução de N. Ramos-de-Oliveira, B. Pucci e C. B. M. Abreu. Primeira Versão, Porto Velho: Edufro, v. XIII, n. 191, p. 44-60, maio/ago. 2005.

ADORNO, T. W.; HORKHEIMER, M. Dialética do esclarecimento: fragmentos filosóficos. Tradução de G. A. Almeida. Rio de Janeiro: Zahar, 1985.

APPLE, M. W.; AU, W.; GANDIN, L. A. (org.). Educação crítica: análise internacional. Porto Alegre: Artmed, 2011.

BAUMAN, Z. Modernidade e Holocausto. Tradução de M. Penchel. Rio de janeiro: Jorge Zahar, 1998.

BITTAR, E. C. B. Educação e metodologia para os direitos humanos: cultura democrática, autonomia e ensino jurídico. In: SILVEIRA, R. M. G. et al. (org.). Educação em direitos humanos: fundamentos teórico-metodológicos. João Pessoa: Editora Universitária, 2007. p. 301-334.

ELEY, G. Forjando a democracia: a história da esquerda na Europa, 1850-2000. São Paulo: Fundação Perseu Abramo, 2005.

FREIRE, P. Pedagogia da autonomia: saberes necessários à prática educativa. 57. ed. Rio de janeiro; São Paulo: Paz e Terra, 2018.

FREIRE, P. Pedagogia do oprimido. 54. ed. Rio de janeiro: Paz e Terra, 2013.

FORRESTER, V. O horror econômico. Tradução de A. Lorencini. São Paulo: Editora da Universidade Estadual Paulista, 1997.

HORKHEIMER, M. Teoria tradicional e teoria crítica. In: TEXTOS escolhidos: Walter Benjamin, Max Horkheimer, Theodor W. Adorno e Jürgen Habermas. Tradução de J. L. Grünnewald et al. São Paulo: Abril Cultural, 1983. (Coleção Os Pensadores). p. 117-154.

HORKHEIMER, M.; ADORNO, T. W. Temas básicos da sociologia. Tradução de Á. Cabral. São Paulo: Cultrix; Editora da Universidade de São Paulo, 1973.

LAVAL, C. A escola não é uma empresa: o neoliberalismo em ataque ao ensino público. Londrina: Planta, 2004.

LUXEMBURGO, R. Textos escolhidos. Organização de I. Loureiro. São Paulo: Unesp, 2011. Volume I (1899-1914).

MAAR, W. L. Teoria crítica como teoria social. In: PUCCI, B.; COSTA, B. C. G. da; DURÃO, F. A. (org.). Teoria crítica e crises: reflexões sobre cultura, estética e educação. Campinas: Autores Associados, 2012. (Coleção Educação Contemporânea).

MARCUSE, H. Algumas implicações sociais da tecnologia moderna. In: MARCUSE, H. Tecnologia, guerra e fascismo. Tradução de Maria Cristina V. Borba. São Paulo: Unesp, 1999. p. 73-104.

MARSDEN, K. Em direção a uma síntese entre o crescimento econômico e a justiça social. $R e$ vista de Administração de Empresas, São Paulo, v. 14, n. 3, p. 113-132, jun. 1974. Disponível em: https://dx.doi.org/10.1590/S0034-75901974000300010. Acesso em: 10 fev. 2019.

MARX, K.; ENGELS, F. A Sagrada Família: a crítica da Crítica Crítica contra Bruno Bauer e consortes. Tradução de Marcelo Backes. São Paulo: Boitempo, 2003.

MÉSZÁROS, I. A educação para além do capital. 2. ed. São Paulo: Boitempo, 2008. 
MÉSZÁROS, I. Estrutura social e formas de consciência II: a dialética da estrutura e da história. São Paulo: Boitempo, 2011.

PUCCI, B. Teoria crítica da sociedade; categorias, análises, reflexões. In: SILVA, L. B. O.; BARCELLOS, A. C. K.; MARCON, G. B. (org.). Sobre teóricos e temas relevantes em educação. São Carlos: Pedro \& João Editores, 2011.

SHERMANN, J. H.; HUNT, E. K. História do pensamento econômico. 25. ed. Petrópolis: Vozes, 2010.

SINGER, P. O capitalismo, sua evolução, sua lógica e sua dinâmica. São Paulo: Moderna, 1987.

STREECK, W. Tempo comprado: a crise adiada do capitalismo democrático. Coimbra: Actual, 2013. 